Document downloaded from:

http://hdl.handle.net/10251/79654

This paper must be cited as:

Oroval, M.; Coronado Puchau, M.; Langer, J.; Sanz-Ortiz, MN.; Ribes, A.; Aznar, E.; Coll Merino, MC.... (2016). Surface Enhanced Raman Scattering and Gated Materials for Sensing Applications: The Ultrasensitive Detection of Mycoplasma and Cocaine. Chemistry A European Journal. 22(38):13488-13495. doi:10.1002/chem.201602457.

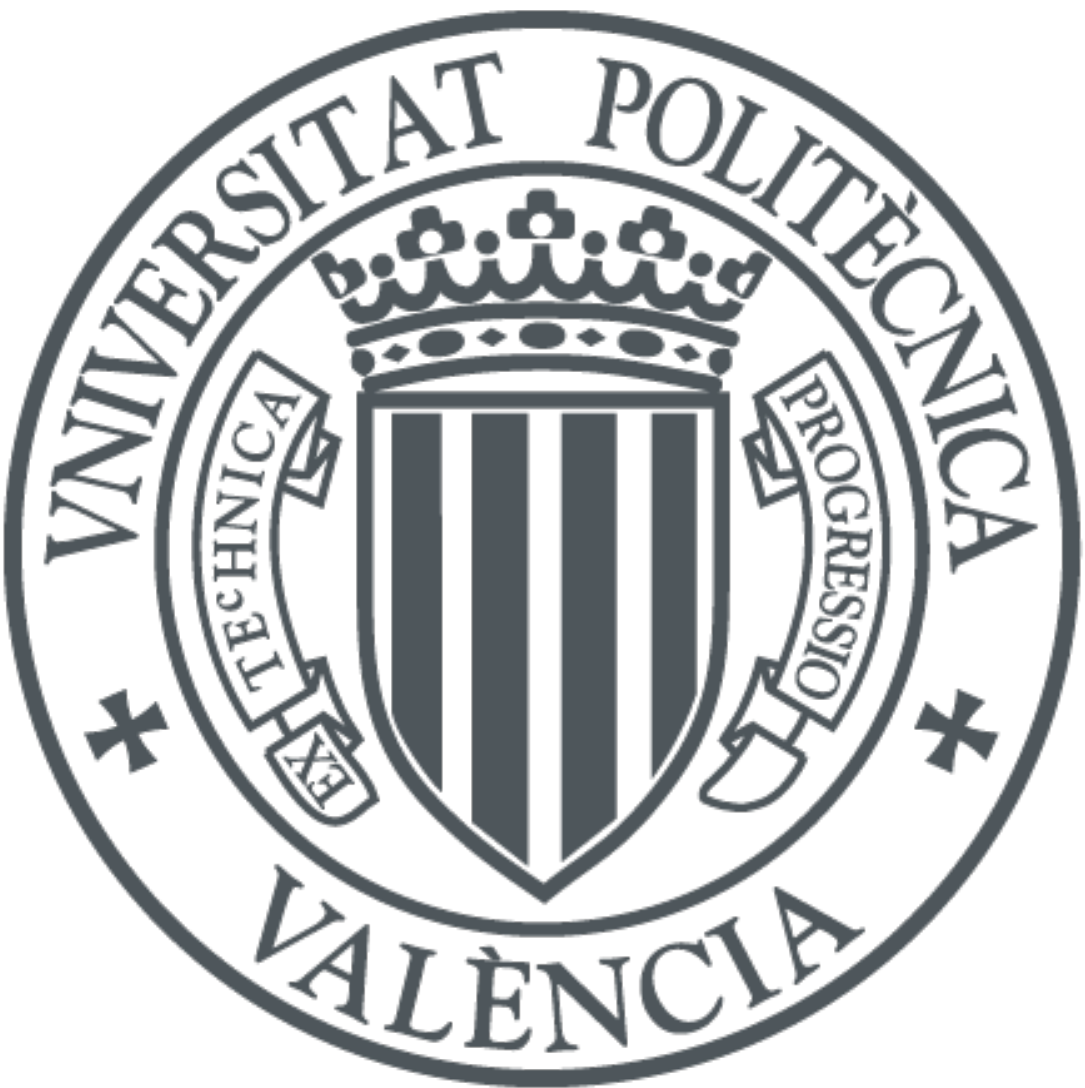

The final publication is available at

http://dx.doi.org/10.1002/chem.201602457

Copyright Wiley

Additional Information 


\title{
Surface Enhanced Raman Scattering and Gated Materials for Sensing Applications. The Ultrasensitive Detection of Mycoplasma and Cocaine
}

\author{
Mar Oroval, ${ }^{[\mathrm{a}],[\mathrm{[e]}}$ Marc Coronado-Puchau, ${ }^{[\mathrm{c}]}$ Judith Langer, ${ }^{[\mathrm{c}]}$ Marta Norah Sanz-Ortiz, ${ }^{[\mathrm{c}]}$ Ángela \\ Ribes, ${ }^{[a],[e]}$ Elena Aznar, ${ }^{[a],[e]}$ Carmen Coll, ${ }^{[a]}$ María Dolores Marcos, ${ }^{[a],[b],[e]}$ Félix Sancenón, ${ }^{[a],[b],[e]}$ Luis M. \\ Liz-Marzán*[c],[d],[e] and Ramón Martínez-Máñez*[a],[b],[e]
}

\begin{abstract}
We present herein a novel combination of gated mesoporous silica nanoparticles (MSNs) and surface-enhanced Raman scattering (SERS) for sensing applications. As a proof of concept, we show the design of a system comprising MSNs loaded with crystal violet (CV), a molecule with high Raman cross section acting as SERS reporter, and capped with either a suitable DNA sequence for the detection of Mycoplasma genomic DNA, or with an aptamer that selectively coordinates cocaine. In both cases the presence of the corresponding target analyte in solution (genomic DNA or cocaine) resulted in the release of CV. CV delivery was detected by SERS upon adsorption on gold nanotriangles (AuNT), which display efficient electromagnetic field enhancement and high colloidal stability. Using this novel procedure a limit of detection of at least 30 copies $\mu \mathrm{L}^{-1}$ was determined for the detection of Mycoplasma genomic DNA, whereas cocaine was detected at concentrations as low as $10 \mathrm{nM}$.
\end{abstract}

\section{Introduction}

Recent advances in nanotechnology and molecular and biomolecular chemistry have resulted in significant advances in areas such as bio-engineering, bio-sensing and bionanotechnology. ${ }^{[1-3]}$ In this scenario materials obtained by anchoring organic molecules to pre-designed inorganic scaffolds resulted in the design of hybrid systems with a wide variety of new functionalities. ${ }^{[4,5]}$ An interesting application in this field is

[a] M. Oroval, A. Ribes, Dr. M.D Marcos, Dr. F. Sancenón, Dr. E. Aznar, Dr. C. Coll, Prof. R. Martínez-Máñez Instituto Interuniversitario de Investigación de Reconocimiento Molecular y Desarrollo Tecnológico. Unidad Mixta Universitat Politècnica de València - Universitat de València. Camino de Vera s/n, 46022, Valencia, Spain

[b] Dr. M.D Marcos, Dr. F. Sancenón, Prof. R. Martínez-Máñez Departmento de Química, Universitat Politècnica de València, Camino de Vera s/n, 46022 València, Spain

[c] Dr. M. Coronado-Puchau, Dr. J. Langer, Dr. M. N. Sanz-Ortiz, Prof. L. M. Liz-Marzán

Bionanoplasmonics Laboratory, CIC biomaGUNE, Paseo de Miramón 182, 20009 Donostia - San Sebastián, Spain

[d] Prof. L. M. Liz-Marzán Ikerbasque, Basque Foundation for Science, 48013 Bilbao, Spain

[e] M. Oroval, A. Ribes, Dr. E. Aznar, Dr. M.D Marcos, Dr. F. Sancenón, Prof. R. Martínez-Máñez, Prof. L. M. Liz-Marzán CIBER de Bioingeniería, Biomateriales y Nanomedicina (CIBER-BBN), Spain

Supporting information for this article is given via a link at the end of the document. the development of gated nano-devices that can deliver an entrapped cargo when selected external stimuli are applied. These gated materials consist of a suitable inorganic support that acts as a nanocontainer and a switchable "gate-like" ensemble capable of being "opened" or "closed" at-will. ${ }^{[6,7]}$ Mesoporous silica nanoparticles (MSNs) are suitable inorganic scaffolds in gated ensembles because they contain tailor-made homogeneous pores of ca. 2-10 nm, are highly inert, easy to functionalise via well-known chemistries, and have a remarkable load capacity dictated by large specific surface area and specific volume. ${ }^{[8,9]} \mathrm{MSN}$ s have been functionalised with a wide variety of switchable molecular, supramolecular and bio-molecular porecapping systems to develop gated materials capable of showing "zero release". These capped materials have been used mainly in drug delivery applications. ${ }^{[10-12]}$ In contrast, their use in sensing protocols is still uncommon and relatively few examples are available. ${ }^{[13,14]}$ For the development of sensory nanoprobes based on MSNs, the inorganic scaffold is loaded with a suitable reporter and the capping mechanism is designed so that only the target analyte is able to induce pore opening and delivery of the reporter (usually a fluorophore). ${ }^{[13,15-17]}$

On the other hand, surface enhanced Raman scattering (SERS) is a highly sensitive, vibrational spectroscopic technique that allows the detection of molecules at very low concentrations, additionally providing structural information. ${ }^{[18-22]}$ The efficiency of SERS is dependent on two effects: (i) the electromagnetic field enhancement provided by excitation of localized surface plasmon resonances (LSPRs) and (ii) the chemical enhancement provided by the electronic interaction between adsorbed molecules and the surface. Gold nanoparticles (AuNPs) in particular have been extensively used because of their high chemical stability and the possibility to tailor their LSPRs over the visible and near infrared (NIR) wavelength ranges, ${ }^{[23]}$ which are most appropriate for Raman scattering measurements. ${ }^{[24-26]}$ As a consequence, AuNPs have been used for SERS detection of many different biological targets including simple biomolecules, proteins, and living cells. ${ }^{[27-38]}$

In this scenario, we envisioned SERS as a complementary detection technique, in combination with capped MSNs, as a suitable approach for the design of novel sensing applications. In previous reports on capped materials for sensing, the recognition event was typically monitored by changes in fluorescence or colour induced by the selective delivery of a dye from the mesoporous support. ${ }^{[13,39]}$ Using a different approach, we were interested in taking advantage of the high performance that SERS offers for the development of sensing platforms, definitely rivalling with other optical measurements such as fluorescence. ${ }^{[40,41]}$ Based on these concepts, a convenient 
design of the SERS-based capped system can be envisioned, so that selective uncapping of MSNs in the presence of the target analyte leads to release of a highly Raman-active molecule (acting as Raman reporter) that is readily detected using suitable dispersed plasmonic nanoparticles (here acting as SERS sensor). When the Raman reporters are stored in the MSN carriers, they are too far away from the metal nanoparticle surface and the SERS effect does not occur, but when released upon analyte-triggered uncapping, SERS signals arise. We propose that this simple design could contribute to the development of highly specific and ultra-sensitive nanodevices for quick identification of a wide variety of target molecules and biomolecules. To demonstrate the general proof-of-concept of this approach, we present here two different detection systems. Both of them comprise MSNs carriers loaded with crystal violet (CV), as efficient Raman reporter at $633 \mathrm{~nm}$ excitation energy, and capped with an oligonucleotide which was specifically devised for the detection of either Mycoplasma fermentans genomic DNA or cocaine. In both cases, the addition of the corresponding target analyte (genomic DNA or cocaine) induces the displacement of the oligonucleotide from the MSNs (due to preferential oligonucleotide coordination with the analytes) and $\mathrm{CV}$ release that is detected by SERS in the presence of gold nanotriangles (AuNTs). A representation of the sensing paradigm is illustrated in Scheme 1.

\section{Results and Discussion}

\section{Design of the detection protocol and sensing material}

Mesoporous MCM-41 nanoparticles were synthesized in alkaline media following well-known procedures that make use of the cationic surfactant $n$-cetyltrimethylammonium bromide (CTAB) as directing agent for condensation of the inorganic precursor tetraethylorthosilicate (TEOS). ${ }^{[42]}$ The obtained powder was washed and the surfactant was subsequently removed by calcination. Then, the obtained MSNs were loaded with a dye (CV), followed by grafting of (3-aminopropyl)triethoxysilane (APTES) on the external surface (S1). Aminopropyl moieties are partially charged at neutral $\mathrm{pH}$ and display electrostatic interactions with negatively charged oligonucleotides. Addition of the oligonucleotide $\mathbf{0 1}$ (see Table 3), a sequence highly conserved in the Mycoplasma genome that corresponds to a fragment of the $16 \mathrm{~S}$ ribosomal RNA subunit, ${ }^{[43,44]}$ resulted in capping of the pores (solid S1-O1). Hybridization of the capping oligonucleotide with Mycoplasma genomic DNA is expected to induce MSNs pore opening ${ }^{[45,46]}$ and dye release, which would be then adsorbed on the $\mathrm{Au}$ nanoparticles, thereby facilitating detection by SERS spectroscopy. As cargo for the mesoporous carrier CV was chosen, which is an efficient Raman scatterer at $633 \mathrm{~nm}$ because of (i) the matching of molecular resonance and excitation wavelength and (ii) quenching of the fluorescence background contribution due to the open, non-radiative relaxation channels.

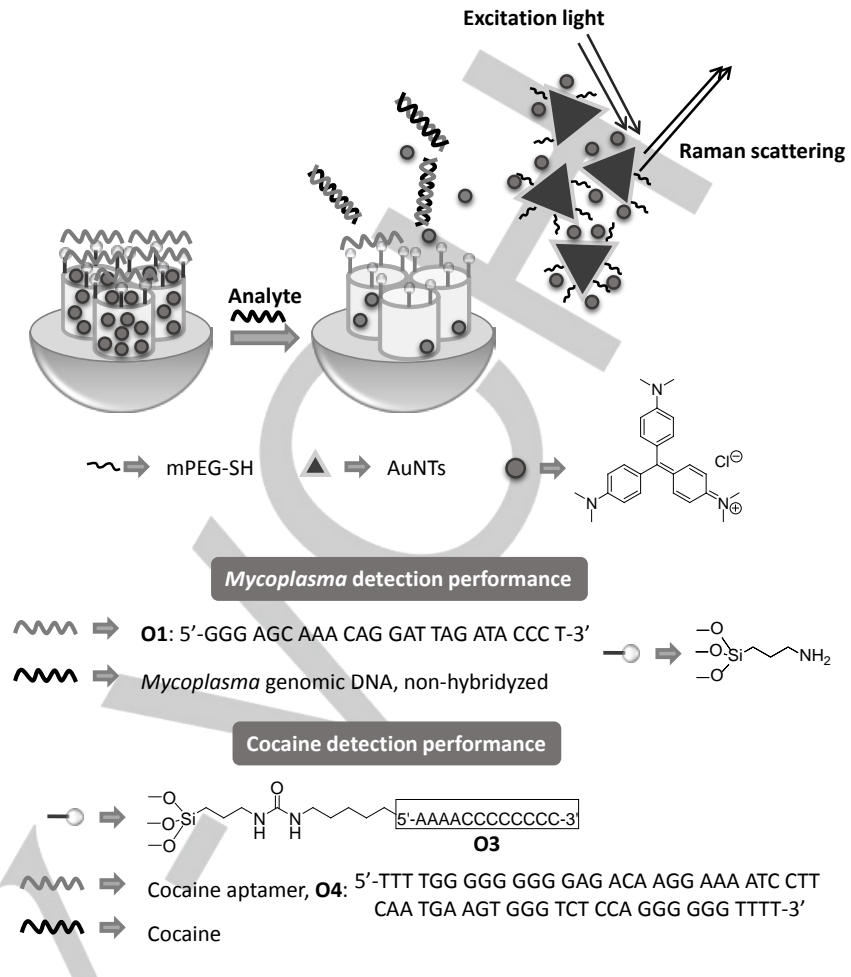

Scheme 1. Representation of the sensing paradigm for Mycoplasma genomic DNA and cocaine detection by means of capped MSNs and SERS.

The approach followed for cocaine detection was identical, except that the CV-loaded MCM-41 support was functionalised on the external surface with (3-isocyanatopropyl)triethoxysilane (S2) and then, a short DNA sequence functionalised with an aminohexyl moiety at the 5'-end position, $\mathbf{0 3}$ (see Table 3), was covalently attached through formation of urea bonds (solid S2O3). Finally, addition of $\mathbf{0 4}$ (which binds specifically to cocaine with high affinity, $K_{d}=0.4-10 \mu \mathrm{M}^{[47]}$ ) blocked the pore outlets by hybridization with the immobilized oligonucleotide $\mathbf{0 3}$. This resulted in the final solid S2-04. The presence of cocaine in solution was expected to displace the aptamer from the solid, due to the selective aptamer-drug interaction, with subsequent pore opening and dye release. Again, the signalling event is recorded via the SERS signal of $\mathrm{CV}$.

An additional task toward the design of the detection system was the optimization of the plasmonic SERS sensor. SERS efficiency is highly dependent on the morphology of the nanoparticles, as it governs the resulting surface plasmon resonance properties. Among the different available shapes, spherical gold nanoparticles are easy to prepare and to functionalise but anisotropic gold nanoparticles have been shown to display more efficient SERS activity due to larger electromagnetic field enhancement at sharp edges or corners compared to those in smooth gold spheres. ${ }^{[48,49]}$ In order to overlap the plasmon band with the laser excitation wavelength, we prepared gold nanotriangles (AuNTs) as a promising candidate for Raman signal amplification. Figure 1 shows the morphology and morphology-dependent LSPR band position for AuNT $\left(\lambda_{\max }=630 \mathrm{~nm}\right)$ and $13 \mathrm{~nm}$ Au nanospheres $\left(\lambda_{\max }=520\right.$ $\mathrm{nm})$. Moreover, the corresponding SERS performance of these 
two nanoparticle morphologies was tested in solutions containing $\mathrm{CV}$ at a concentration of $1 \mu \mathrm{M}$ (Figure 1D). This experiment confirmed that SERS of even the highly Ramanactive $\mathrm{CV}$, was below the detection threshold using $\mathrm{Au}$ nanospheres, due to the moderate electromagnetic field enhancement, ${ }^{[50]}$ but SERS signals were clearly observed when using anisotropic AuNTs. Thus, AuNTs were selected and applied in the subsequent experiments. An additional challenge however was the stabilization of (relatively large) AuNTs in a medium with high ionic strength (20 mM Tris - $37.5 \mathrm{mM} \mathrm{MgCl}_{2}$ ), which was required to facilitate DNA hybridization. We therefore investigated the stabilization of the nanoparticles functionalised with a thiolated polyethyleneglycol ligand (mPEG-SH). In particular, AuNTs were functionalised with ca. $10 \mathrm{mPEG}-\mathrm{SH}$ molecules/nanoparticle (AuNT@PEG), which was found to be enough to preserve the stability of the nanoparticles without affecting CV adsorption. As shown in Figure S4, quenching of CV fluorescence was observed in the presence of AuNT@PEG indicating that the dye was indeed located in the proximity of the nanoparticles.
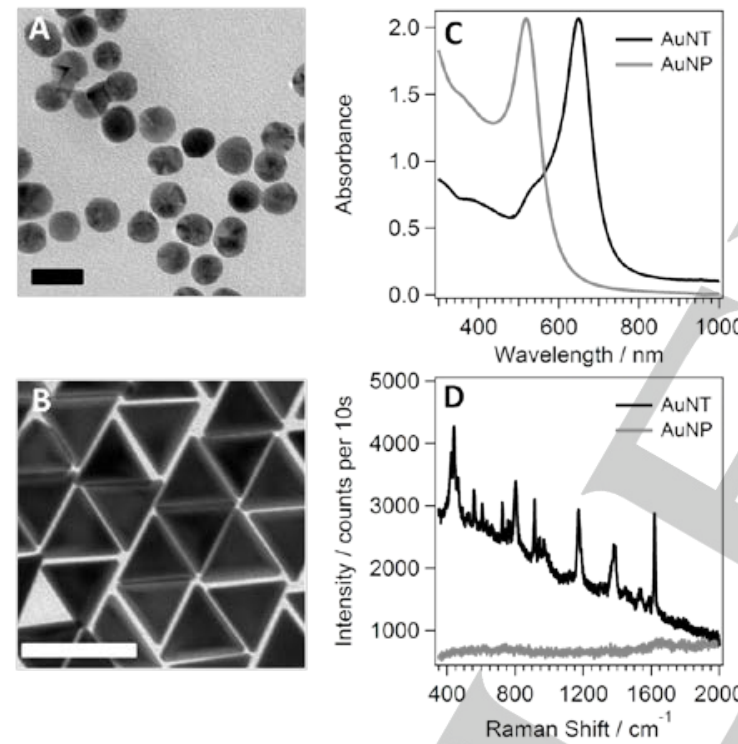

Figure 1. A: TEM images of $13 \pm 1 \mathrm{~nm}$ AUNP. Scale bar: $20 \mathrm{~nm}$. B: TEM image of $(66 \pm 3) \times 25 \mathrm{~nm}$ AuNT. Scale bar: $100 \mathrm{~nm}$. C: UV-vis-NIR spectra of gold nanoparticle colloids. Gold nanospheres (AuNP, grey curve) and gold nanotriangles (AuNT, black curve). D: SERS performance of isotropic vs. anisotropic gold nanoparticles. SERS signal of a $1 \mu \mathrm{M}$ CV solution containing AuNT@PEG (black line) and 13 nm AuNP@PEG (grey line). Both spectra were not background corrected. Measurement parameters were: laser power $1.2 \mathrm{~mW}$, integration time $10 \mathrm{~s}$ (extended scan).

Prior to applying the detection procedure to relevant biomolecules by $\mathrm{CV}$ release, we verified the expected linear relationship between dye concentration and SERS intensity using pure CV aqueous solutions within $5.00-0.05 \mu \mathrm{M}$ concentration range with AuNTs at a concentration of $0.04 \mathrm{mM}$ $\mathrm{Au}^{0}$ corresponding to $[\mathrm{AuNT}]=2.4 \cdot 10^{-10} \mathrm{M}$ (Figure S1A). All the characteristic vibrations at 1619, 914, 1382, 1171 and $800 \mathrm{~cm}^{-1}$ corresponding to two $\mathrm{C}-\mathrm{C}$ ring stretch vibrations, the $\mathrm{C}$ centre- $\mathrm{C}$ stretch, $\mathrm{C}-\mathrm{H}$ ring deformation in-plane and out-of-plane mode were detected. ${ }^{[51]}$ The intensity of the most prominent vibration at $1619 \mathrm{~cm}^{-1}$ was found to follow a linear response within the 5.0 to $0.4 \mu \mathrm{M}$ and 0.4 to $0.05 \mu \mathrm{M}$ concentration ranges (Figure S1B).

\section{Characterisation of the gated mesoporous silica nanoparticles}

MSN-based materials were characterised by using standard techniques. Powder X-ray diffraction of MCM-41 as-synthesized (curve a in Figure 2) showed four low-angle reflections, typical of a hexagonal mesoporous array that can be indexed as (100), (110), (200), and (210) Bragg peaks. Moreover, the presence and high intensity values of the (100) reflections in calcined MCM-41 and in $\mathbf{S 1}$ and $\mathbf{S 2}$ (curves b, c and $d$ in Figure 2) evidencing that the loading with $\mathrm{CV}$ and further functionalisation processes of the external surface did not modify the 3D mesoporous structure. Furthermore, analysis of TEM images of all the materials confirmed the presence of the mesoporous structure and the typical channels of the MCM-41 network were visualised as alternate dark and light stripes (see Figure 2). TEM images also showed that MCM-41 support and solids S1 and S2 are spherical particles of $c a .100 \mathrm{~nm}$ diameter.
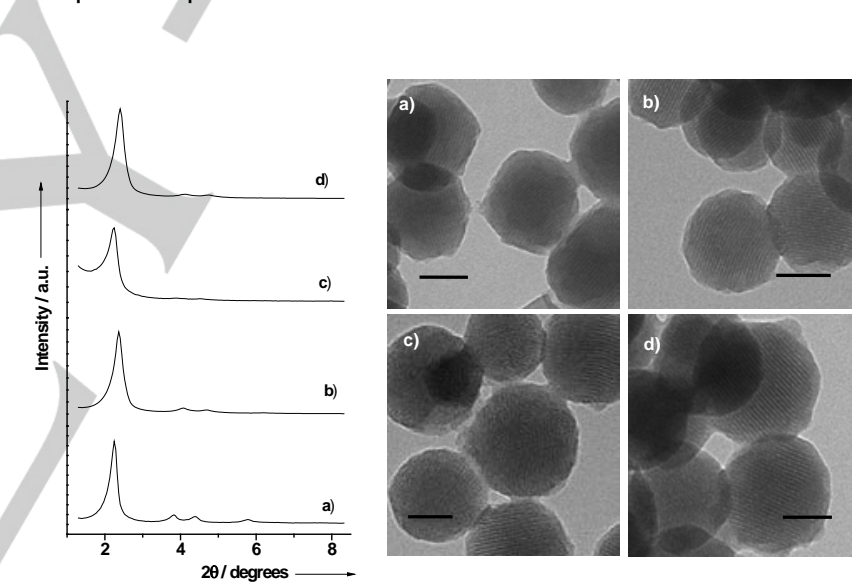

Figure 2. Left panel: Powder X-ray patterns of the solids: (a) MCM-41 as synthesised, (b) calcined MCM-41, (c) solid S1 containing CV and functionalised with APTES, and (d) solid S2 containing CV and functionalised with (3-isocyanatopropyl)triethoxysilane. Right panel: TEM images of: (a) MCM-41 as prepared, (b) calcined MCM-41 sample, (b) solid S1 and (c) solid S2, showing the typical hexagonal porosity of the MCM-41 mesoporous matrix. Scale bar: $50 \mathrm{~nm}$.

In order to complete the characterisation of the MSNs, $\mathrm{N}_{2}$ adsorption-desorption measurements were carried out. For all materials, pore volume was calculated by applying the $\mathrm{BJH}$ model ${ }^{[52]}$ on the adsorption branch of the isotherm (Figure S2) and the total specific surface was calculated by using the BET mode ${ }^{[53]}$ (values are listed in Table 1 ). On the other hand, the $\mathrm{N}_{2}$ adsorption-desorption isotherms of $\mathbf{S} \mathbf{1}$ and $\mathbf{S} 2$ were typical of mesoporous systems with partially filled mesopores (see Figure S2), and a significant decrease in the adsorbed $\mathrm{N}_{2}$ volume and surface area was observed (see Table 1) as a consequence of pore loading (with $\mathrm{CV}$ ) and external functionalisation. Hydrodynamic diameters determined by dynamic light scattering (DLS) and Zeta potential values for solids MCM-41, S1, S1-01, 
S2, S2-03 and S2-04 were determined and are listed in Table S1 (see also Figure S3 and Figure S4).

Table 1. BET specific surface, pore volume and pore size calculated from the $\mathrm{N}_{2}$ adsorption-desorption isotherms for selected materials.

\begin{tabular}{lccc}
\hline Sample & $\begin{array}{c}\mathrm{S}_{\mathrm{BET}} \\
\left(\mathrm{m}^{2} \mathrm{~g}^{-1}\right)\end{array}$ & $\begin{array}{c}\text { Pore volume } \\
\left(\mathrm{cm}^{3} \mathrm{~g}^{-1}\right)\end{array}$ & $\begin{array}{c}\text { Pore diameter } \\
(\mathrm{nm})\end{array}$ \\
\hline MCM-41 & 1055.5 & 0.86 & 2.62 \\
S1 & 98.5 & 0.19 & - \\
S2 & 637.9 & 0.42 & - \\
\hline
\end{tabular}

On the other hand, the organic content in the functionalised nanoparticles were determined by elemental and thermogravimetric analyses (see Table 2). In addition, the content of oligonucleotide in $\mathrm{S1-01,} \mathbf{5 2 - 0 3}$ and $\mathbf{5 2 - 0 4}$ was calculated by measuring the absorbance of the oligonucleotides O1, $\mathbf{O 3}$ and $\mathbf{0 4}$ at $260 \mathrm{~nm}$ after the capping process. Contents of $0.168,0.017$ and $0.085 \mathrm{mmol} \mathrm{g}^{-1}$ of solids, were determined for 01, 03 and 04, respectively.

Table 2. Content of APTES, (3-isocyanatopropyl)triethoxysilane and CV

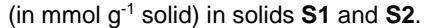

\begin{tabular}{cccc}
\hline Solid & $\begin{array}{c}\alpha_{\mathrm{CV}} \\
\left(\mathrm{mmol} \mathrm{g}^{-1} \mathrm{SiO}_{2}\right)\end{array}$ & $\begin{array}{c}\alpha_{\mathrm{APTES}} \\
\left(\mathrm{mmol} \mathrm{g}^{-1} \mathrm{SiO}_{2}\right)\end{array}$ & $\begin{array}{c}\alpha_{\text {isocyanate }} \\
\left(\mathrm{mmol} \mathrm{g}^{-1} \mathrm{SiO}_{2}\right)\end{array}$ \\
\hline S1 & 0.57 & 2.87 & - \\
S2 & 0.53 & - & 0.31 \\
\hline
\end{tabular}

\section{Mycoplasma detection}

Mycoplasma refers to a genome of prokaryotic microorganisms that have been described as parasites of various animals and plants. ${ }^{[54]}$ In addition, their characteristic lack of a cell wall confers them resistance to many common antibiotics so they are often present in research laboratories as cell-culture contaminants. Hence, detection of these microorganisms is of general interest in biomedical and life sciences. For these experiments, S1-01 in the presence of AuNT@PEG was used. As stated above, a sequence highly conserved in the Mycoplasma genome, that corresponds to a fragment of the $16 \mathrm{~S}$ ribosomal RNA subunit (01), acted as cap for the MSNs. ${ }^{[43,44]}$ In a first batch of experiments the functionality of the system was analysed by adding $\mathbf{O 2}$ (an 01 complementary DNA strand) to a suspension of S1-01 (see experimental section). Three noncomplementary oligonucleotides (05, 06, and 07) were also tested and used as specificity controls. In all cases CV release was monitored by both fluorescence and SERS (Figure S6 and S7) and the system was then optimized for SERS detection. These studies showed that the S1-O1-AuNT@PEG system allowed us to selectively detect extremely low concentrations of $\mathbf{O} 2$ at the nanomolar range (Figure S7), whereas no SERS signal was obtained in the presence of the non-complementary oligonucleotides 05, 06 and 07 (Figure S8).

After confirming the selective gate opening with the complementary oligonucleotide, the response of S1-01 in the presence of Mycoplasma fermentans genomic DNA was studied to explore the correlation between concentration of genomic DNA within the range of 200 to 20 copies $\mu \mathrm{L}^{-1}$ and amount of released $\mathrm{CV}$. To the supernatant of each sample, we added a solution containing AuNT@PEG reaching a final concentration of $0.04 \mathrm{mM} \mathrm{Au}^{0}$ ([AuNT] $=2 \cdot 4 \cdot 10^{-10} \mathrm{M}$ ) and measured the concentration-dependent SERS spectra (Figure 3). The recorded scattered frequencies are in good agreement $(\Delta< \pm 3$ $\mathrm{cm}^{-1}$ ) with previously reported SERS spectra for CV. ${ }^{[55]}$ From these studies it was observed that, in the absence of the Mycoplasma genomic DNA, solid S1-01 was tightly capped and showed a very low release of the dye (which we defined as reference). In contrast, the presence of the target DNA induced uncapping of the pores and $\mathrm{CV}$ release. Regarding the sensitivity of this new approach, after subtraction of the reference signal, the CV SERS signal was clearly detectable at concentrations as low as 30 DNA copies $\mu^{-1}$ of Mycoplasma fermentans. The detection of 20 copies $\mu \mathrm{L}^{-1}$ might be possible (see low signal at $1617 \mathrm{~cm}^{-1}$ ) but under current conditions the signal-to-noise ratio is too low to be correctly determined. Apart from that, the 30 DNA copies $\mu \mathrm{L}^{-1}$ limit represents an improvement when compared with previous works using gated materials. ${ }^{[56,57]}$ The concentration-dependent SERS intensity was plotted as function of the number of DNA copies (Figure 3B) and could be linearly fitted.
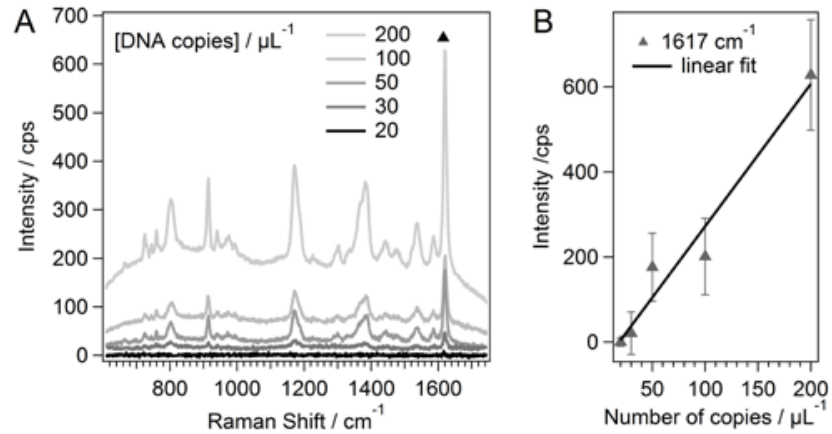

Figure 3. A: Detection of $\mathrm{CV}$ release as a function of the number of Mycobacterium fermentans genomic DNA copies $\mu \mathrm{L}^{-1}$. The SERS signal of CV is detectable for concentrations as low as 30 DNA copies $\mu \mathrm{L}^{-1}$. The SERS spectra were obtained by subtraction of analyte spectra and the corresponding reference spectrum (without analyte) and an offset was applied for [DNA] $=30$ $\mu \mathrm{L}^{-1}$ for clearer data presentation. B: Plot of $1617 \mathrm{~cm}^{-1}$ peak intensity (black triangle in A) and as function of DNA concentration and linearly fitted (black line) according to the function: $y=(3.4 \pm 0.4) x-(62 \pm 42)$. Signal intensities were determined after applying baseline correction. Error bars were calculated from two independent experiments.

Similar experiments with solid S1-01 were carried out to verify the selectivity of the method, in which the genomic DNA of the pathogens Legionella pneumophilia and Candida albicans were used at a concentration of 100 copies $\mu \mathrm{L}^{-1}$ (Figure 4). SERS analysis demonstrated that solid S1-01 responds preferably to the presence of Mycoplasma fermentans genomic 
DNA as an approximately $64 \%$ lower $\mathrm{CV}$ signal was detected in the supernatant in the presence of DNA from other pathogens.

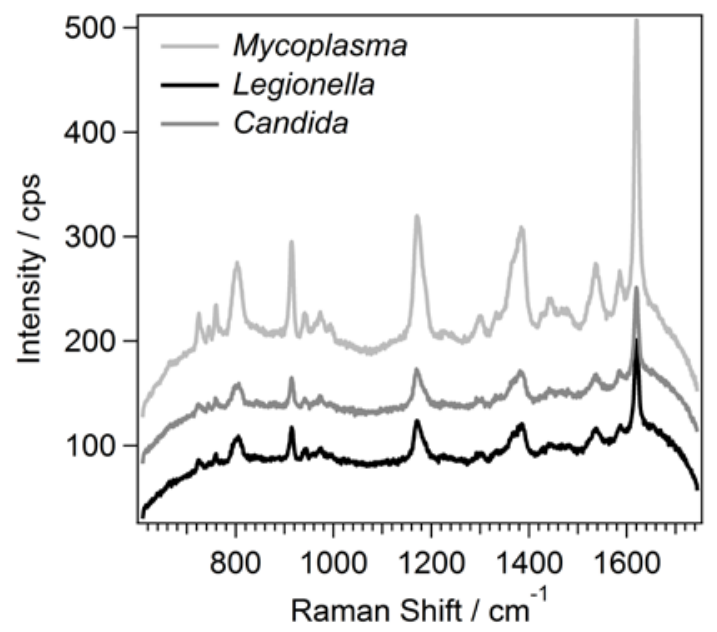

Figure 4. SERS detection of $\mathrm{CV}$ release in the presence of different types of genomic DNA: Mycoplasma fermentans (light grey curve), Legionella pneumophilia (black curve) and Candida albicans (dark grey curve). Genomic DNA concentration was set to 100 copies $\mu \mathrm{L}^{-1}$. Spectra were not corrected and an offset was applied for clearer data representation

\section{Cocaine detection}

Encouraged by the results obtained for S1-01, we devised a second biosensor, again using capped MSNs and SERS, aimed at cocaine detection. Cocaine is an alkaloid obtained from the leaves of the coca plant, which is extensively used in developed countries as an illegal recreational drug. Although cocaine production and distribution is restricted and illegal in most contexts, it is a powerful nervous system stimulant that causes strong addiction among consumers, frequently leading to serious health, social and legal problems. Therefore, development of selective and sensitive devices for its detection is of high importance. ${ }^{[58-60]}$ Our cocaine sensing system comprised MSNs loaded with $\mathrm{CV}$, functionalised with the short DNA sequence $\mathbf{0 3}$ and finally capped with the cocaine aptamer (O4), resulting in the final S2-04 material.
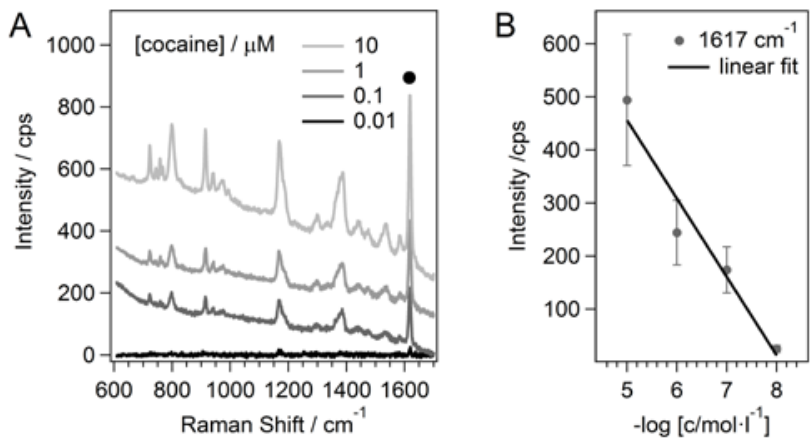

Figure 5. A: Detection of CV release as a function of cocaine concentration The most intense characteristic SERS peak of CV at $1617 \mathrm{~cm}^{-1}$ (black dot) was clearly detected at a concentration as low as $10 \mathrm{nM}$. The SERS spectra were obtained by subtraction of analyte spectra and corresponding reference spectra (without analyte) and an offset was applied for clearer data representation. B: Plot of the most intense SERS peak (grey dots) at $1617 \mathrm{~cm}$ 1 as a function of cocaine concentration and linearly fitted (black line) according to the function: $y=-(147 \pm 24) x+(1194 \pm 160)$. Error bars were calculated from two independent experiments.

Subsequently, we studied the response of the prepared sensing nanocarrier S2-04 toward the presence of cocaine solutions in the $10 \mu \mathrm{M}$ to $10 \mathrm{nM}$ concentration range. CV release was detected by addition of a solution containing AuNT@PEG to the supernatant to reach a final $\mathrm{Au}^{0}$ concentration of $0.02 \mathrm{mM}$ $\left([\right.$ AuNT $\left.]=1.2 \cdot 10^{-10} \mathrm{M}\right)$ which was then monitored by SERS as a function of cocaine concentration (Figure $5 \mathrm{~A}$ ). The results clearly demonstrated that the interaction of cocaine with the aptamer triggers pore opening, allowing dye delivery and detection by SERS.

Upon optimization of the system, the most intense vibrations at 1617 and $1172 \mathrm{~cm}^{-1}$ of $\mathrm{CV}$ were detected by SERS at a cocaine concentration as low as $10 \mathrm{nM}$, indicating a high sensitivity as this result is comparable to those for other aptameric sensors based on fluorescence, ${ }^{[47,60]}$ colorimetric ${ }^{[61,62]}$ or electrochemical measurements. ${ }^{[63,64]}$ Our results additionally provide an improvement of approximately 20 -fold in the detection limit as compared to previous SERS-based aptameric cocaine sensors, ${ }^{[60]}$ which confirms that this method is suitable for the ultrasensitive and highly selective detection of cocaine. The concentration-dependent SERS intensity was also plotted as function of the negative logarithmic cocaine concentration showing a linear response (Figure 5B). Furthermore, control experiments were also carried out to determine the specificity of the system. Experiments in the absence of drug (reference) and in the presence of other drugs such as morphine, methadone and heroine showed that $\mathbf{S 2 - O 4}$ was highly selective to the presence of cocaine in the selected concentration range (Figure 6 ), since no cargo release was detected in the presence of other drugs.

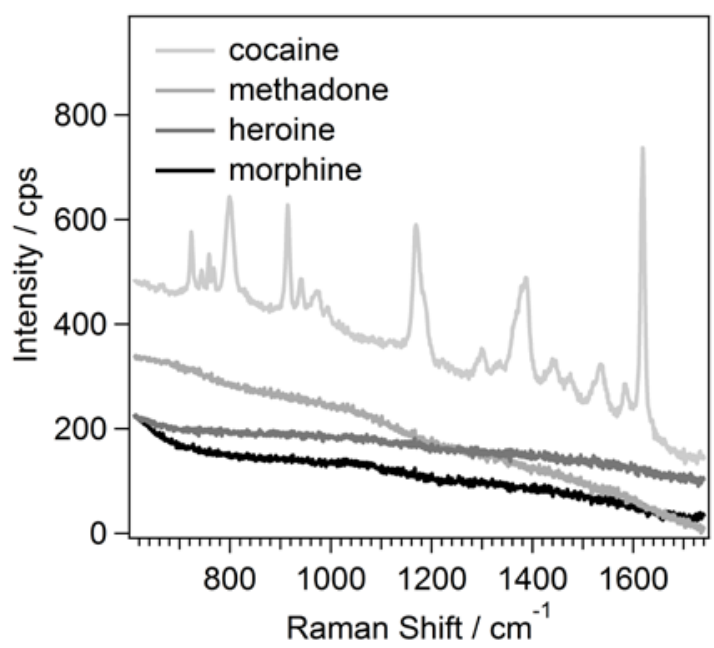

Figure 6. Detection of $\mathrm{CV}$ release in the presence of different drugs. Drug concentration was $10 \mu \mathrm{M}$ in all cases. The SERS spectra were obtained by subtraction of drug spectra and corresponding reference spectra (absence of drug) and an offset was applied for clearer data representation. 


\section{Conclusions}

We have demonstrated, for the first time, that the combination of gated materials with SERS spectroscopy can be used for the design of highly sensitive and selective sensing systems. As a proof-of-concept, CV-loaded MSNs were used in combination with suitable caps and AuNT@PEG for the detection of Mycoplasma genomic DNA and cocaine. In both cases a highly selective and sensitive response was found. We propose that a wide variety of SERS-active molecules can be used as cargo in different capped systems, which can be selectively opened in the presence of specific target analytes and combined with SERS efficient plasmonic nanoparticles, rendering this approach appealing and full of potential for the design of new sensing systems.

\section{Experimental Section}

Materials: Hexadecyltrimethylammonium chloride (CTAC, 25 wt \% in water), hydrogen tetrachloroaurate trihydrate $\left(\mathrm{HAuCl}_{4} \cdot \mathrm{H}_{2} \mathrm{O}, \geq 99.9 \%\right)$, crystal violet (CV, $\geq 90 \%)$, L-ascorbic acid (AA, $\geq 99 \%)$, O-[2-(3mercaptopropionylamino)ethyl]-O'-methylpolyethylene glycol (mPEG-SH, average MW: 5.000), sodium borohydride $\left(\mathrm{NaBH}_{4}, \quad 99 \%\right)$, tetraethylorthosilicate (TEOS), (3-isocyanatopropyl)triethoxysilane, sodium hydroxide (NaOH), (3-aminopropyl)triethoxysilane (APTES), hydrochloric acid, $n$-cetyltrimethylammonium bromide (CTAB, $\geq 99 \%$ ) and tris(hydroxymethyl)aminomethane (Tris) were purchased from Aldrich. Milli-Q water (resistivity $18.2 \mathrm{M} \Omega \cdot \mathrm{cm}$ at $25^{\circ} \mathrm{C}$ ) was used in all experiments. The oligonucleotides and aptamers listed in Table 3 were provided by Isogen Life Science. Analytical-grade solvents were from Scharlab (Barcelona, Spain). Cocaine hydrochloride, morphine, methadone and heroin hydrochloride were provided by the Agencia Española de Medicamentos y Productos Sanitarios (AEMPS). All chemicals were used as received.

Table 3. Oligonucleotides and aptamers used in this work

\begin{tabular}{|c|c|}
\hline Name & Sequence \\
\hline $\mathrm{O} 1$ & 5'-GGGAGCAAACAGGATTAGATACCCT-3' \\
\hline $\mathrm{O} 2$ & 5'-AGGGTATCTAATCCTGTTTGCTCCC-3' \\
\hline $\mathrm{O} 3$ & $\mathrm{NH}_{2-}\left(\mathrm{CH}_{2}\right)_{6}-5$ '-AAAACCCCCCCC-3' \\
\hline $\mathrm{O} 4$ & 5'-TTTGGGGGGGGGAGACAAGGAAAATCCTTCAATGA \\
\hline & AGTGGGTCTCCAGGGGGGTTTT-3' \\
\hline $\mathrm{O} 5$ & 5'-GAGGTTAACAGAGTGACAGATGGTGCA-3' \\
\hline O6 & 5'-AGGGTATCTAATTGCCTGTTGCTCCC-3' \\
\hline 07 & 5'-AGGGTATCTAATGGACCTGTTTGCTCCC-3' \\
\hline
\end{tabular}

General techniques: XRD, TG analysis, elemental analysis, TEM microscopy, $\mathrm{N}_{2}$ adsorption-desorption and UV-visible spectroscopy techniques were used to characterise the prepared materials. X-ray measurements were performed on a Brücher AXS D8 Advance diffractometer using $\mathrm{Cu}-\mathrm{Ka}$ radiation. TEM images of MSNs were taken with a JEOL TEM-1010 Electron microscope working at $100 \mathrm{kV}$. TEM images of AuNPs were collected with a JEOL JEM-1400PLUS instrument operating at $120 \mathrm{kV} . \mathrm{N}_{2}$ adsorption-desorption isotherms were recorded on a Micromeritics ASAP2010 automated sorption analyzer. The samples were degassed at $120{ }^{\circ} \mathrm{C}$ in vacuum overnight. The specific surfaces areas were calculated from the adsorption data in the low pressures range using the $\mathrm{BET}$ model. Pore size was determined following the $\mathrm{BJH}$ method. Fluorescence spectroscopy was carried out on a Jasco FP-8300 Spectrometer. Optical extinction spectra were recorded using an Agilent 8453 UV-vis diode-array spectrophotometer. SERS measurements were performed by means of Renishaw in Via system consisting of a confocal
Leica microscope equipped with high-resolution diffraction grating (1800 $\mathrm{gr} \mathrm{mm}^{-1}$ ), band pass filter optics and a Peltier-cooled CCD detector using a HeNe laser ( $\lambda=633 \mathrm{~nm}$, maximal output $12.5 \mathrm{~mW}$ ) as excitation source. All spectra were measured with a long-working distance 50x objective having a numerical aperture of 0.45 from samples in solution within a 1 $\mathrm{mL}$ glass vial (Thermo Scientific). If not otherwise stated, scattered frequencies were collected for $1 \mathrm{~s}$ at irradiation power (Plaser) of $6 \mathrm{~mW}$ and 100 spectra were accumulated from each sample. Corresponding to each Mycoplasma genomic DNA and cocaine concentration an individual reference measurement without respective analyte was performed Concentration dependent SERS data presented here were then plotted as intensity difference between the averaged sample and averaged reference spectrum.

Buffer solutions: Hybridization buffer consisting in $20 \mathrm{mM}$ Tris- $\mathrm{HCl}, 37.5$ $\mathrm{mM} \mathrm{MgCl} 2(\mathrm{pH} 7.5)$ in Milli-Q water, was used for controlled release experiments.

Synthesis of MCM-41 mesoporous nanoparticles: An aqueous solution of $\mathrm{NaOH}(2 \mathrm{M}, 3.5 \mathrm{~mL})$ was added to a solution of CTAB $(1.00 \mathrm{~g}$, $2.74 \mathrm{mmol})$ in deionized $\mathrm{H}_{2} \mathrm{O}(480 \mathrm{~mL})$. The solution temperature was adjusted to $80^{\circ} \mathrm{C}$. TEOS ( $5 \mathrm{~mL}, 2.5710^{-2} \mathrm{~mol}$ ) was subsequently added dropwise to the surfactant solution. The mixture was stirred for $2 \mathrm{~h}$ to yield a white precipitate. The final solid was centrifuged, washed with deionized water and dried at $70{ }^{\circ} \mathrm{C}$ for $18 \mathrm{~h}$ (MCM-41 as-synthesized). To obtain the final porous material (MCM-41), the as-synthesized solid was calcined at $550{ }^{\circ} \mathrm{C}$ under oxidizing atmosphere for $5 \mathrm{~h}$ to remove the template.

Synthesis of S1: The amino functionalised solid S1 was prepared as follows: calcined MCM-41 (500 mg) and CV (161 mg, $0.4 \mathrm{mmol})$ were suspended in Milli-Q water $(20 \mathrm{~mL})$. The suspension was stirred at room temperature for $24 \mathrm{~h}$ to load the MCM-41 pores. Afterward an excess of APTES (0.65 mL, $2.77 \mathrm{mmol}$ ) was added, and the suspension was stirred at room temperature for $5.5 \mathrm{~h}$. Finally, the resulting solid was isolated by filtration, washed with Milli-Q water $(3 \mathrm{~mL})$ and dried at $36{ }^{\circ} \mathrm{C}$ for $18 \mathrm{~h}$.

Synthesis of S1-01: For the preparation of S1-01, of $\mathbf{S 1}(450 \mu \mathrm{g})$ was suspended in of a solution $(450 \mu \mathrm{L})$ containing the oligonucleotide $\mathbf{O} \mathbf{1}$ in a concentration of $40 \mu \mathrm{M}$ in hybridization buffer, and the suspension was stirred at $37{ }^{\circ} \mathrm{C}$ for 30 minutes. The final S1-01 solid, was isolated by centrifugation and washed with of hybridization buffer $(3 \times 1 \mathrm{~mL})$ in order to remove the residual dye and the free oligonucleotide $\mathbf{0 1}$.

Synthesis of S2: In a typical synthesis, calcined MCM-41 (300 mg) and CV (98 mg, $0.24 \mathrm{mmol}$ ) were suspended in $\mathrm{CH}_{3} \mathrm{CN}(10 \mathrm{~mL})$. The suspension was stirred at room temperature for $24 \mathrm{~h}$ to load the pores. Then, an excess of (3-isocyanatopropyl)triethoxysilane $(0.37 \mathrm{~mL}, 1.5$ $\mathrm{mmol}$ ) was added, and the suspension was stirred at room temperature for $5.5 \mathrm{~h}$. Finally, the resulting solid was isolated by filtration, washed with $3 \mathrm{~mL}$ of $\mathrm{CH}_{3} \mathrm{CN}$ and dried at $36^{\circ} \mathrm{C}$ for $18 \mathrm{~h}$.

Synthesis of S2-03: Oligonucleotide $\mathrm{O3}(100 \mu \mathrm{L})$ was added to a suspension containing S2 $(1 \mathrm{mg})$, triethylamine $(2 \mu \mathrm{L})$ and $\mathrm{CV}$ in $\mathrm{CH}_{3} \mathrm{CN}$ $(700 \mu \mathrm{L}, 1 \mathrm{mM})$. The mixture was stirred at room temperature for $3 \mathrm{~h}$. The final solid S2-03 was isolated by centrifugation and washed with Milli-Q water $(2 \times 700 \mu \mathrm{L})$ to eliminate the unbounded oligonucleotide and the dye.

Synthesis of S2-04: In order to cap the pores of solid S2-03, a portion of S2-03 $(200 \mu \mathrm{g})$ was suspended in a solution $(400 \mu \mathrm{L})$ containing the cocaine aptamer in a concentration of $5 \mu \mathrm{M}$ in hybridization buffer. The suspension was stirred at room temperature for $2 \mathrm{~h}$, and the final solid S2-04 was centrifuged and washed with hybridization buffer to remove the free cocaine aptamer and the residual dye. 
Gold nanoparticles synthesis: Citrate stabilized Au NPs (13 nm), were prepared by the Turkevich method. ${ }^{[65]}$ Briefly, Au NPs were prepared by injecting sodium citrate $(25 \mathrm{~mL}, 1.7 \mathrm{mM})$ to the boiling solution of $\mathrm{HAuCl}_{4}$ $(500 \mathrm{~mL}, 0.5 \mathrm{mM})$. The color of the solution changes from colorless to dark red after $10 \mathrm{~min}$ of reaction.

Gold nanotriangles synthesis: AuNT@PEG were synthesized by a recently reported seeded growth method. ${ }^{[66]}$ In a typical experiment two growth solutions are prepared: 1) $1.6 \mathrm{~mL}$ of $0.1 \mathrm{M}$ CTAC solution was added to $8 \mathrm{~mL}$ of Milli-Q water, followed by $40 \mu \mathrm{L}$ of $0.05 \mathrm{M} \mathrm{HAuCl}_{4}$ and by $15 \mu \mathrm{L}$ of $0.01 \mathrm{M} \mathrm{Nal}$ solutions; 2) $500 \mu \mathrm{L}$ of $0.05 \mathrm{M} \mathrm{HAuCl}_{4}$ solution was added to $40 \mathrm{~mL}$ of $0.05 \mathrm{M} \mathrm{CTAC}$, followed by $300 \mu \mathrm{L}$ of $0.01 \mathrm{M} \mathrm{Nal}$ solution. The first solution was used to grow the CTAC capped seed into larger nanoparticles, while the second solution was used as the NTs growth batch. Before proceeding, the initial seed@CTAC solution was diluted $10 \times$ in a 0.1 M CTAC solution. Subsequently, $40 \mu \mathrm{L}$ and $400 \mu \mathrm{L}$ of $0.1 \mathrm{M}$ AA solution were added to solutions 1 and 2, respectively, and both solutions were manually stirred until the complete transparency of the solutions was achieved. Finally, $100 \mu \mathrm{L}$ of diluted seed@CTAC solution was added to solution 1 (and manually stirred for 1 second), and immediately $3.2 \mathrm{~mL}$ of this solution was added to solution 2 (and manually stirred for a few seconds). The AuNTs dispersion was left undisturbed at room temperature for at least 1 hour. Then, the AuNTs dispersion was purified by addition of $6.65 \mathrm{~mL}$ of $25 \mathrm{wt} \%$ CTAC solution to reach a final CTAC concentration of $0.15 \mathrm{M}$. Flocculation of the AuNTs was completed overnight, the supernatant was then removed and the precipitated particles were redispersed in $5 \mathrm{~mL}$ of $0.1 \mathrm{M} \mathrm{CTAC}$ solution. After TEM characterisation the AuNTs were centrifuged (4000 rpm, 15 min, $30{ }^{\circ} \mathrm{C}$ ) and stabilized with a suitable amount of mPEG-SH, calculated to add 10 thiols/NP. The solution was left stirring overnight for proper functionalisation. Then, it was centrifuged (4000 rpm, $15 \mathrm{~min}$, $\left.30{ }^{\circ} \mathrm{C}\right)$, and the supernatant was carefully removed. The pellet was finally redispersed in Milli-Q water.

Release experiments of S1-01: To investigate the gating properties of S1-01, $450 \mu \mathrm{g}$ of this solid was suspended in $1.7 \mathrm{~mL}$ of hybridization buffer and separated in two aliquots of $850 \mu \mathrm{L}$ each. As a control experiment (reference), each first fraction was diluted with $150 \mu \mathrm{L}$ of Milli$\mathrm{Q}$ water at $50^{\circ} \mathrm{C}$. Whereas each second one (sample) was treated with $150 \mu \mathrm{L}$ of an aqueous solution containing different concentrations of oligonucleotide $\mathbf{0 2}$. In both cases, the suspensions were stirred for 60 $\min$ at $37^{\circ} \mathrm{C}$. In order to remove the solid, both fractions were centrifuged $\left(8000 \mathrm{rpm}, 3 \mathrm{~min}, 20^{\circ} \mathrm{C}\right.$ ). Dye delivery was then immediately measured by the fluorescence emission of $\mathrm{CV}$ in the solution at $620 \mathrm{~nm}\left(\lambda_{\mathrm{exc}}=590\right.$ $\mathrm{nm})$.Subsequently, $20 \mu \mathrm{L}$ of AuNT@PEG solution containing around $\left[\mathrm{Au}^{0}\right]=0.04 \mathrm{mM}$ (estimated using the absorbance at $400 \mathrm{~nm}^{[67]}$ ) was added to each sample/reference for CV SERS detection. For the release experiments in the presence of Mycoplasma genomic DNA, $1 \mathrm{mg}$ of S1$\mathbf{O} 1$ was suspended in $1 \mathrm{~mL}$ of hybridization buffer and then two aliquots were taken from this suspension. Meanwhile, a solution containing genomic double-stranded DNA (dsDNA) of Mycoplasma fermentans standard $\left(10^{3}\right.$ DNA copies $\left.\mu \mathrm{L}^{-1}\right)$ was heated at $95{ }^{\circ} \mathrm{C}$ for $5 \mathrm{~min}$ to dehybridize dsDNA and then cooled to $50{ }^{\circ} \mathrm{C}$. The DNA solution was added to one of the aliquots to reach a final DNA concentration of 20,30, 50,100 or 200 copies $\mu \mathrm{L}^{-1}$ whereas Milli-Q water (without DNA) at $50{ }^{\circ} \mathrm{C}$ was added to the second aliquot. Both suspensions were maintained at $37^{\circ} \mathrm{C}$ and after 1 hour the mixtures were centrifuged to remove the solid.

Release experiments of S2-04: $200 \mu \mathrm{L}$ of S2-04 solution $\left(500 \mu \mathrm{g} \mathrm{mL}^{-1}\right)$ was suspended in $800 \mu \mathrm{L}$ of hybridization buffer. Then, this suspension was divided in two aliquots and a proper amount of aqueous cocaine solution ( $2 \mathrm{mM}$ ) was added to one of the aliquots (samples) to reach a final cocaine concentration of $10^{-5}, 10^{-6}, 10^{-7}$ or $10^{-8} \mathrm{M}$, respectively. At the same time, an equal amount of Milli-Q water (without cocaine) was added to the other aliquot (reference). The suspensions were kept at room temperature and after 1 hour it was centrifuged $(8000 \mathrm{rpm}, 3 \mathrm{~min}$ $20{ }^{\circ} \mathrm{C}$ ) to remove the solid. Subsequently, $10 \mu \mathrm{L}$ of AuNT@PEG solution containing around $\left[\mathrm{Au}^{0}\right]=0.02 \mathrm{mM}$ ([AuNT@PEG]= $1.2 \times 10^{-10} \mathrm{M}$ ) was added to each sample/reference for CV SERS detection.

\section{Acknowledgements}

M.C.-P. acknowledges an FPU Scholarship from the Spanish Ministry of Education, Culture and Sports. L.M.L.-M. acknowledges the financial support from the European ResearchCouncil (ERC Advanced Grant \#267867 Plasmaquo). M.O is grateful to the Universitat Politècnica de València for her FPI-UPV grant. Financial support from the Spanish Government (Project MAT2015-64139-C4-1-R) and the Generalitat Valenciana (Project PROMETEOII/2014/047) is gratefully acknowledged.

Keywords: gated materials - surface enhanced Raman spectroscopy • biosensors $\cdot$ cocaine $\cdot$ Mycoplasma

[1] R. P. Goodman, I. a T. Schaap, C. F. Tardin, C. M. Erben, R. M. Berry, C. F. Schmidt, a J. Turberfield, Science 2005, 310, 1661-1665.

[2] M. Nishikawa, S. Rattanakiat, Y. Takakura, Adv. Drug Deliv. Rev. 2010, 62, 626-32.

[3] A. Mahapatro, Mater. Sci. Eng. C 2015, 55, 227-251.

[4] A. B. Descalzo, R. Martínez-Máñez, F. Sancenón, K. Hoffmann, K. Rurack, Angew. Chem. Int. Ed. 2006, 45, 5924-48.

[5] K. Ariga, Y. Yamauchi, Q. Ji, Y. Yonamine, J. P. Hill, APL Mater. 2014, 2, 030701.

[6] C. Coll, A. Bernardos, R. Martínez-Máñez, F. Sancenón, Acc. Chem. Res. 2013, 46, 339-49.

[7] Y. Klichko, N. M. Khashab, Y.-W. Yang, S. Angelos, J. F. Stoddart, J. I. Zink, Microporous Mesoporous Mater. 2010, 132, 435-441.

[8] A. Baeza, M. Colilla, M. Vallet-Regi, Expert Opin. Drug Deliv. 2015, 12, 319-337.

[9] C. Argyo, V. Weiss, C. Bräuchle, T. Bein, Chem. Mater. 2014, 26, 435451.

[10] a) S. Koutsopoulos, Adv. Drug Deliv. Rev. 2012, 64, 1459-1476; b) G. Bao, S. Mitragotri, S. Tong, Annu. Rev. Biomed. Eng. 2013, 15, 25382; c) P. Yang, S. Gai, J. Lin, Chem. Soc. Rev. 2012, 41, 3679-3698.

[11] R. Qian, L. Ding, H. Ju, J. Am. Chem. Soc. 2013, 135, 13282-13285.

[12] E. Aznar, M. Oroval, L. Pascual, J. R. Murguía, R. Martínez-Máñez, F. Sancenón, Chem. Rev. 2016, 116, 561-718

[13] F. Sancenón, L. Pascual, M. Oroval, E. Aznar, R. Martínez-Máñez, ChemistryOpen 2015, 4, 418-437.

[14] K. Ren, J. Wu, Y. Zhang, F. Yan, H. Ju, Anal. Chem. 2014, 86, 74947499 .

[15] E. Climent, D. Gröninger, M. Hecht, M. A. Walter, R. Martínez-Máñez, M. G. Weller, F. Sancenón, P. Amorós, K. Rurack, Chem. Eur. J. 2013 19, 4117-22.

[16] S. Wu, X. Huang, X. Du, Angew. Chem.Int. Ed. 2013, 52, 5580-5584.

[17] E. Aznar, R. Villalonga, C. Giménez, F. Sancenón, M. D. Marcos, R. Martínez-Máñez, P. Díez, J. M. Pingarrón, P. Amorós, Chem. Commun. 2013, 49, 6391-6393. 
[18] S. Sarkar, S. Dutta, T. Pal, J. Phys. Chem. C 2014, 118, 28152-28161.

[19] K. Kneipp, Y. Wang, H. Kneipp, L. T. Perelman, I. Itzkan, R. R. Dasari, M. S. Feld, Phys. Rev. Lett. 1997, 1667-1670.

[20] W. Ma, H. Yin, L. Xu, X. Wu, H. Kuang, L. Wang, C. Xu, Chem. Commun. 2014, 50, 9737.

[21] A. La Porta, A. Sánchez-Iglesias, T. Altantzis, S. Bals, M. Grzelczak, L. M. Liz-Marzán, Nanoscale 2015, 7, 10377-10381.

[22] H. Xie, Y. Lin, M. Mazo, C. Chiappini, A. Sánchez-Iglesias, L. M. LizMarzán, M. M. Stevens, Nanoscale 2014, 6, 12403-7.

[23] H. U. I. Wang, D. W. Brandl, Acc. Chem. Res. 2007, 40, 53-62.

[24] A. Shiohara, Y. Wang, L. M. Liz-Marzán, J. Photochem. Photobiol. C Photochem. Rev. 2014, 21, 2-25.

[25] B. Sharma, R. R. Frontiera, A.-I. Henry, E. Ringe, R. P. Van Duyne, Mater. Today 2012, 15, 16-25.

[26] T. Kang, S. M. Yoo, I. Yoon, S. Y. Lee, B. Kim, Nano Lett. 2010, 10, 1189-1193.

[27] L. Polavarapu, A. La Porta, S. M. Novikov, M. Coronado-Puchau, L. M. Liz-Marzán, Small 2014, 10, 3065-71.

[28] D. Cialla, S. Pollok, C. Steinbrücker, K. Weber, J. Popp, Nanophotonics 2014, 3, 383-411.

[29] J. Langer, S. M. Novikov, L. M. Liz-Marzán, Nanotechnology 2015, 26, 322001

[30] A. F. Palonpon, J. Ando, H. Yamakoshi, K. Dodo, M. Sodeoka, S. Kawata, K. Fujita, Nat. Protoc. 2013, 8, 677-692.

[31] S. Siddhanta, C. Naray, Nanomater. Nanotechnol. 2012, 1.

[32] X. X. Han, Y. Ozaki, B. Zhao, TrAC Trends Anal. Chem. 2012, 38, 6778.

[33] L. M. Liz-Marzán. J.J. Giner-Casares, M. Henriksen-Lacey, M. Coronado-Puchau, Mater. Today 2015, 19,19-28.

[34] G. Lu, H. De Keersmaecker, L. Su, B. Kenens, S. Rocha, E. Fron, C. Chen, P. Van Dorpe, H. Mizuno, J. Hofkens, et al., Adv. Mater. 2014, 26, 5124-8.

[35] S. Zong, Z. Wang, H. Chen, J. Yang, Y. Cui, Anal. Chem. 2013, 85, 2223-2230.

[36] G. Zheng, L. Polavarapu, L. M. Liz-Marzán, I. Pastoriza-Santos, J. Pérez-Juste, Chem. Commun. 2015, 51, 4572-4575.

[37] Y. Wang, L. Polavarapu, L. M. Liz-Marzán, ACS Appl. Mater. Interfaces 2014, 6, 21798-21805

[38] P. Quaresma, I. Osório, G. Dória, P. a. Carvalho, A. Pereira, J. Langer, J. P. Araújo, I. Pastoriza-Santos, L. M. Liz-Marzán, R. Franco, et al., RSC Adv. 2014, 4, 3659.

[39] M. Hecht, E. Climent, M. Biyikal, F. Sancenón, R. Martínez-Máñez, K. Rurack, Coord. Chem. Rev. 2013, 257, 2589-2606.

[40] J.-M. Li, W.-F. Ma, C. Wei, L.-J. You, J. Guo, J. Hu, C.-C. Wang, Langmuir 2011, 27, 14539-44.

[41] D.-K. Lim, K.-S. Jeon, H. M. Kim, J.-M. Nam, Y. D. Suh, Nat. Mater. 2010, 9, 60-67.

[42] M. Comes, G. Rodríguez-López, M. D. Marcos, R. Martínez-Máñez, F. Sancenón, J. Soto, L. A. Villaescusa, P. Amorós, D. Beltrán, Angew. Chem. Int. Ed. 2005, 44, 2918-22.

[43] P. C. Choppa, A. Vojdani, C. Tagle, R. Andrin, L. Magtoto, Mol. Cell. Probes 1998, 12, 301-8.

[44] F. J. van Kuppeveld, J. T. van der Logt, A. F. Angulo, M. J. van Zoest, W. G. Quint, H. G. Niesters, J. M. Galama, W. J. Melchers, Appl.
Environ. Microbiol. 1992, 58, 2606-15.

[45] E. Climent, R. Martínez-Máñez, F. Sancenón, M. D. Marcos, J. Soto, A Maquieira, P. Amorós, Angew. Chem. Int. Ed. 2010, 49, 7281-3.

[46] C. Chen, J. Geng, F. Pu, X. Yang, J. Ren, X. Qu, Angew. Chem. Int. Ed. 2011, 50, 882-886.

[47] M. N. Stojanovic, P. de Prada, D. W. Landry, J. Am. Chem. Soc. 2001, 123, 4928-4931.

[48] P. F. Liao, J. Chem. Phys. 1982, 76, 751.

[49] J. Gersten, a Nitzan, J. Chem. Phys. 1980, 73, 3023.

[50] Y. Zhang, B. Walkenfort, J. H. Yoon, S. Schlucker, W. Xie, Phys. Chem. Chem. Phys. 2015, 17, 21120-21126.

[51] W. Meng, F. Hu, L. Y. Zhang, X. H. Jiang, L. D. Lu, X. Wang, J. Mol. Struct. 2013, 1035, 326-331.

[52] E. P. Barrett, L. G. Joyner, P. P. Halenda, J. Am. Chem. Soc. 1951, 73 , 373-380.

[53] S. Brunauer, P. H. Emmett, E. Teller, J. Am. Chem. Soc. 1938, 60 , 309-319.

[54] S. Razin, D. Yogev, Y. Naot, Microbiol. Mol. Biol. Rev. 1998, 62, 1094 156.

[55] M. V. Cañamares, C. Chenal, R. L. Birke, J. R. Lombardi, J. Phys. Chem. C 2008, 112, 20295-20300.

[56] E. Climent, L. Mondragón, R. Martínez-Máñez, F. Sancenón, M. D. Marcos, J. R. Murguía, P. Amorós, K. Rurack, E. Pérez-Payá, Angew. Chem. Int. Ed. 2013, 52, 8938-42.

[57] L. Pascual, I. Baroja, E. Aznar, F. Sancenón, M. D. Marcos, J. R. Murguía, P. Amorós, K. Rurack, R. Martínez-Máñez, Chem. Commun. 2015, 51, 1414-6.

[58] M. N. Stojanovic, D. W. Landry, J. Am. Chem. Soc. 2002, 124, 96789679.

[59] C.-Y. Zhang, L. W. Johnson, Anal. Chem. 2009, 81, 3051-5.

[60] J. Chen, J. Jiang, X. Gao, G. Liu, G. Shen, R. Yu, Chem. Eur. J. 2008, 14, 8374-82.

[61] J. Liu, J. H. Lee, Y. Lu, Anal. Chem. 2007, 79, 4120-5.

[62] F. Xia, X. Zuo, R. Yang, Y. Xiao, D. Kang, A. Vallée-Bélisle, X. Gong, J. D. Yuen, B. B. Y. Hsu, A. J. Heeger, et al., Proc. Natl. Acad. Sci. U. S. A. 2010, 107, 10837-41.

[63] J. Liu, Y. Lu, Angew. Chem. Int. Ed. 2006, 45, 90-94.

[64] B. R. Baker, R. Y. Lai, M. S. Wood, E. H. Doctor, A. J. Heeger, K. W. Plaxco, J. Am. Chem. Soc. 2006, 128, 3138-3139.

[65] J. Kimling, M. Maier, B. Okenve, V. Kotaidis, H. Ballot, A. Plech, J. Phys. Chem. B 2006, 110, 15700-7.

[66] L. Scarabelli, M. Coronado-Puchau, J. J. Giner-Casares, J. Langer, L. M. Liz-Marzán, ACS Nano 2014, 8, 5833-5842.

[67] J. Rodríguez-Fernández, J. Pérez-Juste, P. Mulvaney, L. M. LizMarzán, J. Phys. Chem. B 2005, 109, 14257-14261. 


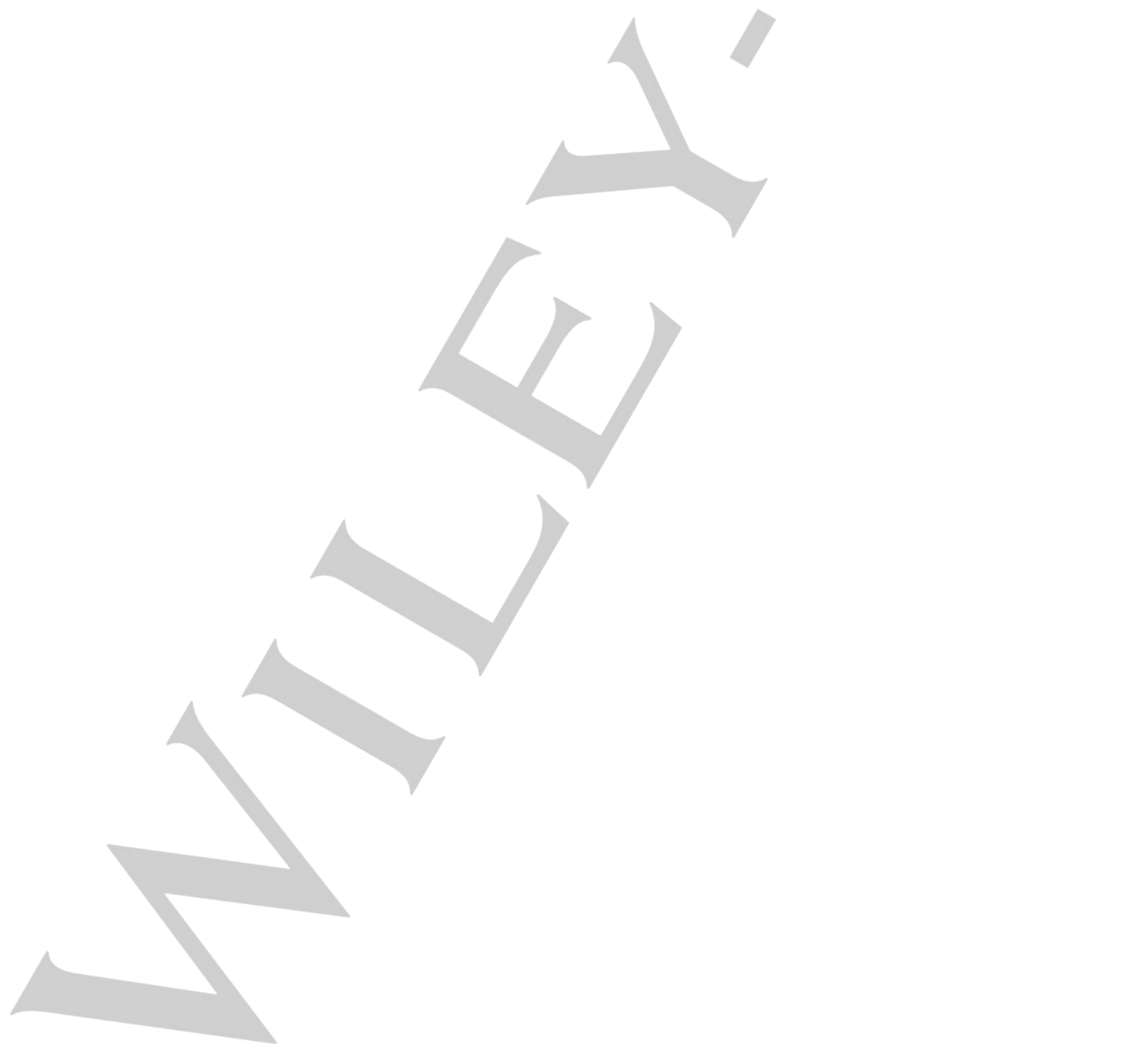




\section{FULL PAPER}

The novel combination of gated materials with SERS spectroscopy for designing highly sensitive and selective sensing systems is presented. CV-loaded MSNs and capped with suitable biomolecules were combined with AuNT@PEG for the detection of Mycoplasma genomic DNA and cocaine.

Remarkable low limits of detection as low as 20 copies $\mu \mathrm{L}^{-1}$ and $10 \mathrm{nM}$, respectively, were obtained.

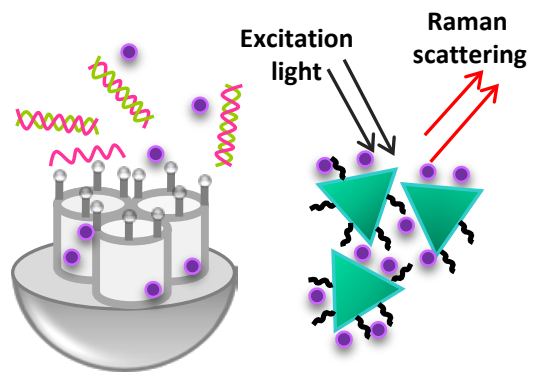

Mar Oroval, Marc Coronado-Puchau, Judith Langer, Marta Norah Sanz-Ortiz, Ángela Ribes, E. Aznar, Carmen Coll, María Dolores Marcos, Félix

Sancenón, Luis M. Liz-Marzán* and Ramón Martínez-Máñez*

Page No. - Page No.

Surface Enhanced Raman Scattering and Gated Materials for Sensing Applications. The Ultrasensitive Detection of Mycoplasma and Cocaine 